Vol. 4, No. 2, Oktober 2020, hlm. 175-183 DOI: $10.37274 /$ rais.v4i02.326

\title{
Model Kurikulum Pendidikan Meningkatkan Etos Kerja Muslim di Lingkungan Kedinasan
}

\author{
Obay Sobari ${ }^{*}$, Ulil Amri Syafri' ${ }^{1}$, Budi Handrianto ${ }^{1}$ \\ ${ }^{1}$ Universitas Ibn Khaldun Bogor, Indonesia \\ *Sobarimuchtar21@gmail.com
}

\begin{abstract}
Abstrak
Permasalahan dalam penelitian ini adalah bagaimana etos kerja muslim yang sebenarnya memuliki segudang konsep baik dari al Quran dan Sunnah, namun banyak ditemukan seorang muslim yang bekerja dengan cara dan gaya yang jauh dari nilai-nilai Islam, terutama sisi etika maupun etos kerja, Untuk itu, penelitian ini bertujuan untuk menngaplikasikan satu model kurikulum untuk meningkatkan etos kerja muslim. Penelitian ini menggunakan metode kajian kepustakaan (liberary reasech) yang bersifat deskriptif kualitatif dengan pengumpulan data primer melalui rujukan kepustakaan, sedangkan data sekunder nya diperoleh melelui wawanacara kepada peajabat,kepala seksi dan beberapa karyawan bea dan cukai kota Bogor. Hasil Penelitian menunjukkan bahwa penerapan konsep kurukulum pendidikan untuk meningkatkan etos kerja muslim di lingkungan kedinasan perlu terus mendapatkan perhatian lebih, baik dari sisi konsep maupun penerapan serta pengawasannya.
\end{abstract}

Kata kunci: Model kurikulum, etos kerja muslim, kedinasan

\begin{abstract}
Problems in this research is how a work ethic muslim Who actually have a wonderful concept of good from Al Qur'an and As Sunnah. But there plenty of found a muslim who worked manner and the force that far from islamic values, especially with ethical or work ethos, Therefor, This research aims to to apply one model curriculum to increase work ethic muslim. This research study using a library reasearch method, that traits of descriptive qualitative with the collection of primary data through of reference main book While secondary data it obtained through interviews to officials, section head, and several employees of Office of customs and excise Bogor. The research results show that The application of the concept of education curriculum to improve muslim work ethos in the government office Need to continue to get more attention, Both in the concept and application and supervision also.
\end{abstract}

Keywords : Curriculum Model, Muslim work ethos, official. 


\section{Pendahuluan}

Islam agama yang sangat bisa membantu menjadi problem solver atas berbagai persoalan umat. Dari konsep saleh secara individu sampai saleh sosial. Bermula dengan hal yang bersifat pribadi dan keluarga sampai masalah urusan profesi. Baik profesi swasta, PNS, bisnis, wiraswasta, perbankkan dan lain-lain. Islam mampu memenuhi semua kebutuhan manusia dalam mengatur berbagai profesi dalam bingkai etika profesi (Adabul Mihnah).

Namun, seiring waktu berjalan. Situasi umat Islampun mengalami kemunduran dari sisi mental dan daya kerja. Umat mengalami tiga masalah besar yang oleh Naquib Al Attas direalis ada tiga : pertama, Rusaknya ilmu ( loss of khowlage). Kedua, rusaknya Adab ( loss Of adab) dan ketiga, lahirnya pemimin-pemipin palsu.

Di hampir semua departeman di negeri ini bermasalah dalam aspek kejujuran atau etika dalam bekerja dan beprofesi. Terutama departeman yang berbau keuangan, Bea dan Cukai, misalnya. Rappler Indonesia merealis tragedi Para anggota Dewan Perwakilan Rakyat Republik Indonesia Periode 2014-2019 yang terlibat kasus korupsi, sebanyak 7 orang. Dan dalam dokumen KPK 4 anggota dewan DPR RI terkena operasi tangkap tangan ( OTT) KPK pada tahun 2018.

Islam sebagai agama yang sempurna (Syumul) dan lengkap (kamil) tentu memiliki banayak jawaban, terhadap prilaku indisipliner di dunia kerja., yang sudah menodai kesucian peradaban dunia kerja yang seharusnya profesional, amanah dan sesuai syariah. Oleh karena itu bagaimana kurikulum Pendidikan meningkatkan Etos Kerja mampu memberikan jawaban atas problematia diatas?

Tentu dengan terus mempelajari dan mengkaji perkembangan dunia kerja, dunia usaha, sebagai upaya agar menjadi acuan dalam memberikan kontribusi terhadap dunia mu'aamalah yang ada di Indonesia dan Islam benar-benar menjadi solusi.

Pengertian Kurikulum Pendidikan Menurut Wan Mohd Nor Wan Daud, bahwa kata pendidikan- tidak diragukan lagi- merupakan wahana terpenting bagi individu dan masyarakat untuk meraih kesejahteraan dan kemajuan. Ahmad Tafsir mengambil pemahaman orang-orang Yunani lebih kurang 600 tahun sebelum Masehi, telah menyatakan bahwa pendidikan ialah upaya membantu manusia menjadi menusia. ( ahmad tafsir, 2010) Sedangkan Hasan Langgulung (w.2008 M) menyatakan : "dengan kata lain pendidikan adalah suatu tindakan (action) yang diambil oleh suatu masyarakat, kebudayaan atau peradaban untuk memelihara kelanjutan hidupnya. Dari pengertianpengertian tersebut di atas dapat ditarik benang merah bahwa, kurikulum pendidikan adalah sebuah program yang terencana dengan baik dan terstruktur secara akurat berisikan muatan materia-materi pembelajaran yang memiliki tujuan-tujuan pasti yang menunjang dunia pendidikan, baik lembaga pendidikan atau lembaga-lembaga yang membutuhkan sistem kurikulum dalam rencana pengembangan Sumber Daya Manusia 
serta merupakan sebuah bantuan atau bimbingan yang membatu menusia agar mampu menemukan tujuan hidupnya.

Pengertian etos kerja muslim menurut Rika Agustin ( 2010) dalam kamus ilmiahnya mengatakan bahwa,, etos : semangat; jiwa, pandangan hidup khas suatu bangsa. Sedangkan dalam kamus besar Bahasa Indonesia (1998), bahwa etos berasal dari bahasa Yunani (etos) yang memberikan arti sikap, kepribadian, watak, karakter, serta keyakinan atas sesuatu. adapun etos kerja adalah semangat kerja yang menjadi ciri khas dan keyakinan seseorang atau suatu kelompok. Jadi etos kerja muslim adalah semangat, kepribadian dan keyakinan akan profesi pekerjaan yang menjadi pandangan dan prinsip bagi seorang muslim.

Pengertian kedinasan, Menelusuri dari Ruka Agustin (2010), kata kedinasan berasal dari kata dinas, yang berarti tugas ( resmi), kepegawaian, kekaryaan. Sedangkan menurut Kamus Besar Bahasa Indonesia (KBBI), kata dinas adalah perihal pekerjaan ( tugas kewajiban) dinas. Bisa diambil kesimpulan, bahwa kedinasan bisa difahami sebagai sebuah ikatan atau kontrak kerja seorang karyawan atau mahasiswa ikatan dinas pada sebuah lembaga yang berada di bawah kooordinasi intruksional langsung dari pemerintah dan mendapat jaminan dari pemerintah tersebut.

\section{Metode Penelitian}

Penelitian ini menggunakan metode kajian kepustakaan (liberary reasech) yang bersifat deskriptif kualitatif dengan pengumpulan data primer melalui rujukan kepustakaan, sedangkan data sekunder nya diperoleh melelui wawancara kepada pejabat, kepala seksi dan beberapa karyawan bea dan cukai kota Bogor. Kemudian penelitian ini hanya menggambarkan gejala atau keadaan yang diteliti secara apa adanya dari data yang bersifat empiris.. Menurut Moleong deskriptif yaitu data yang dikumpulkan berupa kata-kata, gambar, dan bukan angka-angka. Dengan demikian laporan penelitian akan berisi kutipan-kutipan data untuk memberi gambaran penyajian laporan tersebut.

Teknik analisis data dilakukan dengan mengorganisasikan data, memilahmilahnya menjadi satuan yang dapat dikelola, mensintesiskannya, mencari dan menemukan pola, menemukan apa yang penting dan apa yang dipelajari serta memutuskan apa yang dapat diceritakan kepada orang lain. Dalam penelitian ini, peneliti menggunakan analisis induktif yang berarti bahwa kategori, tema dan pola berasal dari data setelah memperoleh data dan terkumpul dari kegiatan lapangan kemudian data dianalisa secara kualitatif dengan tekhnik pengelompokan data untuk selanjutnya diambil kesimpulan.

Usaha pengelompokan data sampai pengambilan keputusan ini dilakukan dengan meringkas deskripsi data menjadi deskripsi terfokus, oleh karenanya dalam teknik 
analisa data pada penelitian ini menggunakan descriptive analysis, atau sering disebut deskriptif analitik yaitu dengan cara memadukan data yang otentik dengan berfikir induksi untuk kemudian menghasilkan kesimpulan (Lexy J Moleong, 2011).

\section{Hasil dan Pembahasan}

Munir (2008) mengemukakan tentang empat pilar standar sebuah kurikulum yang bisa dijalankan di lingkungan kerja atau kedinasan.

\section{Tujuan}

Adapun tujuan dari kurikulum ini adalah :

Pertama, Membina karyawan dalam meningkatkan keimanan dan ketaqwaan kepada Allah SWT. Ahmad Tafsir mengatakan, bahwa membangun kekutan manusia harus dari tiga dimensi; kekuatan jasmani,kekuatan akal atau pikir dan kakuatana rasa. Inilah hakikat menusia menurut Allah SWT.

Sebagaiman firman-Nya : Hai orang-orang yang beriman, bertakwalah kepada Allah sebenar-benar takwa; dan janganlah sekali-kali kamu mati melainkan dalam keadaan beragama Islam. (QS. 3:102)

Hal ini sesuai dengan sabda Nabi Muhammad SAW; Bertaqwalah kepada Allah dimanpun berada, dan ikutiilah perbuatan buruk dengan perbuatan baik untuk menghapusnya dan berakhakhlah dengan bersama manusia dengan akhlak yang mulai. (HR. Attirmidzi).

Kedua, Menumbuhkan karakter kesalehan pribadi maupun kesalehan sosial, Banyak orang yang saleh pribadi, namun bermasalah dalam saleh sosial. Allah SWT berfirman dalam al Quran surat Ali 'Imron ayat 112: Artinya Mereka diliputi kehinaan di mana saja mereka berada, kecuali jika mereka berpegang kepada tali (agama) Allah dan tali (perjanjian) dengann manusia, dan mereka kembali mendapat kemurkaan dari Allah dan mereka diliputi kerendahan. Yang demikian itu karena mereka kafir kepada ayat-ayat Allah dan membunuh para nabi tanpa alasan yang benar. Yang demikian itu disebabkan mereka durhaka dan melampaui batas. (QS. 3:112).

Ketiga, Menumbuhkan rasa takut dan patuh kepada kepada Allah SWT dan kepada aturan-aturan yang berlaku dalam lembaga. Hal ini sejalan dengan firman Allah SWT : Artinya : Hai orang-orang yang beriman, taatilah Allah dan taatilah Rasul (Nya), dan ulil amri di antara kamu. Kemudian jika kamu berlainan pendapat tentang sesuatu, maka kembalikanlah ia kepada Allah (Al Quran) dan Rasul (sunnahnya), jika kamu benar-benar beriman kepada Allah dan hari kemudian. Yang demikian itu lebih utama (bagimu) dan lebih baik akibatnya. (Qs. 4:59).

Keempat, Karyawan memiliki sifat jujur, integritas, komitmen, profesional dan memiliki rasa kepedulian yang tinggi terhadap lembaga. Berikut ayat yang 
menginspirasi poin ini : Artinya : (yaitu) orang-orang yang sabar, yang benar, yang tetap taat, yang menafkahkan hartanya (di jalan Allah), dan yang memohon ampun di waktu sahur. (QS. 3:17).

Kelima, Memilki kemampuan mengevaluasi diri dalam melaksanakan setiap tugas dan tanggung jawabnya. Semangat evaluasi ini termaktub dalam al Quran surat al Haysr ayat 18, yang artinya : Hai orang-orang yang beriman, bertakwalah kepada Allah dan hendaklah setiap diri memperhatikan apa yang telah diperbuatnya untuk hari ekesok (akhirat); dan bertakwalah kepada Allah, sesungguhnya Allah Maha Mengetahui apa yang kamu kerjakan. (QS. 59:18).

Keenam, Menumbuhkan semangat team work dalam bingkai kebersamaan dan keluargaan. Kesesuian tujuan ini terdapat firman Allah SWt, yaitu : Dan berpeganglah kamu semuanya kepada tali (agama) Allah, dan janganlah kamu bercerai berai.. (QS. 3:103)

Ketujuh, Tumbuhnya semangat menguasai dan mengendalikan diri Ini hal sangat mendasar bagi karyawan agar tidak tergoda tawaran-tawaran dunia yang negative yang bisa menggadaikan jabatan. Allah SWT berfirma : Dan aku tidak membebaskan diriku (dari kesalahan), karena sesungguhnya nafsu itu selalu menyuruh kepada kejahatan, kecuali nafsu yang diberi rahmat oleh Tuhanku. Sesungguhnya Tuhanku Maha Pengampun lagi Maha Penyanyang. (QS.12:53).

\section{Isi Materi ( program)}

Adapun program atau materi yang bisa disajikan adalah, sebagi berikut : Pertama, Mengadakan Malam Bina Iman dan Taqwa (MABIT) secara rutin. Pembinaan berjamaah di masjid ini, selain sebagai sebuah ajang silaturrahmi antara karyawan, juga merupakan agenda yang sangat membekas pada diri karyawan, yaitu salat malam dan muhasabah (Introspeksi diri). Ishak (2007), Allah SWT berfirman : Dan pada sebahagian malam hari bersembahyang tahajudlah kamu sebagai suatu ibadah tambahan bagimu; mudah-mudahan Tuhan-mu mengangkat kamu ke tempat yang terpuji. (QS. 17:79).

Kedua, Membina karyawan untuk memiliki visi kerja yang lebih religius. Dalam bukunya antara perut dan etos kerja, Thohir (2001), mengatakan bahwa : Ada perbedaan yang mencolok anatara karyawan yang tidak beragama, atau beragama hanya sekedar simbol, dengan karyawan yang menjadikan agama sebagai bimbingan dan pedoman dalam bekerja sehingga dia terbebas dari apa yang disebut "al ghaayah tubarriru al washiilah" (tujuan menghalalkan segala cara). Baginya, agama adalah conditio sine quo non yang tidak bisa dipisahkan sama sekali dari pekerjaan yang ditekuni. Agama adalah guiding principle 'peinsip yang membimbing' setiap prilaku dalam bekerja. Sedangkan Toto Tasmara (1995), mengatakan, bahwa seorang muslim tidak mungkin memungkiri 
eksistensi dirinya dengan mengabaikan visi dan misi agamanya. Adapun visi kerja religius yang di maksud, adalah: Pertama, bekerja hanyalah bercita-cita meraih fadhilah dan Ridha Allah SWT. Kedua, Mengadakan pelatihan keseimbangan antara dzikir dan pikir.

Ketiga, Mengadakan work shop atau pelatihan kepemimpinan dalam Islam. Setiap manusia memiliki potensi, sebagai pemimpin. Hal ini sdengan sabda Nabi Muhammad Saw : setiap kalian adalah pemimpin ( paling tidak untuk diri sendiri) dan setiap kalian akan ditanya oeh Allah tentang kepempinannya. (HR. Bukhori). Toto menambahkan: salah satu aspek dari nilai etos kerja muslim adalah penghayatan terahadap kesadaran diri, bahwa manusia adalah Kholifah Fil Ardhi, pemimpin dimuka bumi. Yasier (2010) menekankan, bahwa salah satu sifat melekat pada seorang pemimpin, adalah pengaruh.

Keempat, Penghargaan atau award religi karyawan terbaik. Bisa berupa :Pertama, Hajji atau umroh. Kedua, wisata religi. Baik ziyarah para ulama yang masih hidup atau wisata tempat sejarah Islam. Mengapa reward religi ini diperlukan sebagai bagian dari upaya peningkatan etos kerja Islami? karyawan bisa belajar tentang diri dalam proses ibadah haji atau umroh, dan mereka bisa belajar kepada para pahlawan muslim yang telah berjasa membawa Islam ini ke Indonesia ini.

Keenam, Pelatihan khusus membuat Personal Mission Document (PMD) atau atau cetak biru ( blue print) diri. Seperti konsep yang di gagas oleh izzaidin. (2009) Allah menciptakan manusia dengan memiliki potensi keinginan, cinta dan kebutuhan yang luar biasa dan tentu berorientasi untuk masa depan. (QS. 59:18). Dari sini jelaslah, bahwa manusia perlu dirangsang semangat dan etos kerjanya dengan membangun impian dan cita-citanya.

\section{STRATEGI}

Adapun strategi yang di bangun dalam kurikulum ini adalah, seperti apa yang di gagas oleh Abudin Nata (2013), bahwa : pertama, Penyelenggaraan pendidikan etos kerja berbasis nilai-nilai Islam, baik al Quran, Hadis, dakwah, dan tarbiyah. Kedua, Penyelenggaraan pendidikan etos kerja diarahkan pada nilai-nilai semangat juang para pahlawan Islam masa dahulu. Ketiga, Penyelenggaraan pendidikan etos kerja diarahkan pada karakter karyawan Islam yang memiliki sifat egaliter, univertsal, seimbang dan berorientasi pada akhirat. Keempat, Penyelenggaraan pendidikan etos kerja harus diarahkan pada era globalisasi yang menuntut karyawan "melek" akan tentologi dan infomasi yang sesuai dengan nilai-nilai Islam. Dan kelima, Penyelenggaraan pendidikan etos kerja diarahkan pada standar kualitas karyawan Nasional, bahkan bisa bertarap internasional. 


\section{Evaluasi}

Evaluasi yang bisa dilakukan dengan model kurikulum ini adalah : Pertama, evaluasi Kualitatif ( Hasan, 2008), yaitu yang menurut Reichartdt dan cook (1979:9) seperti yang dikutif oleh Hasan, adalah metodologi kualitatif berkembang dari filsafat fenomenologi. Penggunaan metode evaluasi ini menempatkan proses pelaksanaan sebuah kurikulum (program) sebagai fokus utama evaluasi. Oleh karena itu, kurikulum dalam dimensi kegiatan proses lebih mendapatkan perhatian dibanding dengan dimensi lain.

Ada dua hal penting dari evaluasi program ini :

a. Setiap karyawan Mengisi lembar kontrol ( mutaba'ah) : baik pekanan (unbu'iyyah) atau bulanan (syahriyyah). Contoh lembar Evaluasi pekanan dan evaluasi bulanan aspek salat berjamaah di masjid dan pelaksanaan tugastugas kantor, Yasier ( 2013)

$\begin{aligned} & \text { Nama Karyawan } \\
& \text { Bidang Pekerjaan }\end{aligned}$
\begin{tabular}{|c|c|c|c|}
\hline No & $\begin{array}{c}\text { Salat Berjamaah } \\
\text { di mesjid }\end{array}$ & Terlaksana & Tidak Terlaksana \\
\hline 1 & Subuh & $\checkmark$ & \\
\hline 2 & Zuhur & $\checkmark$ & \\
\hline 3 & Asar & $\checkmark$ & \\
\hline 4 & Magrib & $\checkmark$ & \\
\hline 5 & Isya & $\checkmark$ & \\
\hline
\end{tabular}

Kolom Evaluasi ( Mutaba'ah) bulanan tugas-tugas kantor

\begin{tabular}{|c|c|c|c|}
\hline No & $\begin{array}{c}\text { Tugas-tugas dan } \\
\text { kewajiban kantor }\end{array}$ & Terlaksana & Tidak Terlaksana \\
\hline 1. & Selalu tepat waktu & $\checkmark$ & \\
\hline 2. & $\begin{array}{c}\text { Melaksanakan tugas } \\
\text { sesuai JUKNIS dan } \\
\text { JUKLAK }\end{array}$ & $\checkmark$ & \\
\hline 3. & $\begin{array}{c}\text { Membuat pelaporan } \\
\text { selalu sesuai date } \\
\text { line }\end{array}$ & $\checkmark$ & \\
\hline
\end{tabular}




\begin{tabular}{|c|c|c|c|}
\hline 4. & Aplikasi nilai-nilai & & \\
& integritas dan & $\checkmark$ & \\
& komitmen sesuai & $\checkmark$ & \\
sumpah karyawan & & \\
\hline
\end{tabular}

b. Melakukan wawancara kepada pemegang jabatan di wilayah bea dan Cukai kota Bogor dan melihat data perekembangan etos kerja karyawan muslim di kantor tersebut.

Kedua, evaluasi kuantitatif. Evaluasi ini dilakukan jika diperlukan untuk mengukur tingkat keberhasilan sekaligus sebagai pembanding program-program peningkatan etos kerja muslim pada level karyawan di kantor bea dan cukai.

\section{Kesimpulan}

Dicetaknya Program dengan kurikulum yang baik dan diperkaya muatan bimbingan dan pembinaan intensif para karyawan tentu dengan dukungan penuh steikholder perusahaan atau kantor kedinasan. Agar memiliki visi misi kerja yang lebih religius, kesimbangan emosi yang stabil, terbangunnya impian yang jelas di masa depan , semangat diri selalu diawasi oleh Allah SWT (muraqabah), penghargaan atau award religi kepada setiap karyawan yang memiliki etos kerja terbaik, akan masuk akal jika karyawan muslim mampu menampilkan etos kerja yang tidak hanya religius, namun juga penuh dengan integritas dan komitmen yang tinggi.

\section{Daftar Pustaka}

Mubarok, Abadullah Ibnu, Al Zuhdu, upaya mendekatkan diri kepada Allah SWT dan meninggalkan cinta dunia, Jakarta, Pustaka Azzam.

Jabir al jazajiri, Abu Bakar, Munhajul Muslim (terjemah), ummul Quro, 2017

Nata, Abudin, Kapita Selekta Pendidikan Islam,Isu-isu Kontemporer Tentang

Pendidikan Islam, Rajagrafindo Persada, Jakarta, 2013.

Mohd Nor Wan Daud, Wan, Islamisasi Ilmu-ilmu Kontemporer dan Peran Universitas Islam, Dalam Konteks Dewesternisasi dan Dekolonisasi, Bogor, Ibnu Khaldun, 2013.

Munir, kurikulum berbasis teknologi dan informasi, alfabeta, bandung, 2008 Ibnu shahih al-Ishaq Ash-shai'ari, Muhammad, The Spirit Of Tahajjud, menggapai Sukses Melalui Salat Tahajjud, terjemah, Pustaka Nuun, Semarang, 2007.

Tafsir, Ahmad, Filsafat Pendidikan Islam, Integrasi Jasmani dan Kalnu Memanusiakan Manusia, Bandung, PT. Remaja Rosdakarya, 2012.

Luth, Thohir, antara Perut dan Etos Kerja, dalam perpektif Islam, Jakarta, Gema Isani Press, 2001. 
Tasmara, Toto, Etos Kerja Pribadi Muslim,PT. Dana Bhakti Wakaf, Jakarta, 1995.

Utama, Yasier and Team, Leadership In me Training ( modul pelatihan 3 hari), Jakarta, 2010. Leadership in me. Modul Pelatihan Kepemimpinan. Surabaya, 2013

Syamsuddin, Izzaidiin, Awwarness Before Change ( ABC, Modul Pelatihan perubahan diri 3 hari), Bogor, 2009.

Risa Agustin, Kamus Ilmiah Populer lengkap Dengan EYD dan Pembentukan Isltilah Serta Akronim Bahasa Indonesia,

Hasan, Hamid, Evaluasi Kurikulum, Bandung, Sekolah Pascasarjana Universitas Pendidikan Indonesia dengan PT. Rosdakarya, 2008.

Badan Pengembangan dan Pembinaan Bahasa, Kamus Besar Bahasa Indonesia, Balai Pustaka, 1988

Rappler Indonesia adalah jaringan berita sosial di mana berita dan cerita menginspirasi koumunitas dan memicu aksi nyata untuk perubahan sosial.

Mulyadi, E, urikulum Tingkat Satuan Pedidikan,Sebuah Panduan Praktis, Bandung, PT. Remaja Rosdakarya, 2018

Lexy Moleong, Metodologi Penelitian Kualitatif, Bandung: PT Remaja Rosdakarya Offset, 2006.

Khalif, Muammar, makalah seminar :Tiga masalah besar umat menurut Shed Naquib al Attas. Jakarta. 2017

IDN Time KPK, 13 Desember 2018.

TEMPO, 04 April 2018. 